\title{
Escatologia e Messianismo em Is 8,23-9,6
}

\author{
Eschatology and Messianism in Isaiah 8,23-9,6
}

Doaldo Ferreira Belem

\section{Resumo}

O presente trabalho objetiva analisar o caráter messiânico e escatológico na perícope de Is $8,23-$ 9,6. Utilizando o Método Histórico-Crítico e uma definição do conceito de messianismo e escatologia, observa-se muitos elementos escatológicos tais como: esperança por um dia de glória e salvação para Israel; um rei davídico ideal com um novo reino que ultrapassa os limites judaítas; ação efetuada somente por Deus, com sua intervenção na história e exercício do juízo; o fim relativo da história, com a distinção clara de duas épocas e um novo início; o aspecto da definitividade e a profunda relação com a história. Entretanto, falta o aspecto futuro, predominando o passado: portanto, o texto não é escatológico. Quanto ao messianismo, apesar da ausência de títulos messiânicos, Is 8,23-9,6 expressa a esperança de uma modificação radical a partir de um personagem histórico e concreto que ascenda ao trono. Seguramente, o menino descrito na perícope nos é apresentado como o cumprimento último do sinal do Emanuel e, portanto, um personagem claramente messiânico.

Palavras-chave: Livro do profeta Isaías. Escatologia. Messianismo.

\begin{abstract}
The actual essay aims to analyze the messianic and eschatological character in the pericope of Isaiah 8,23-9,6. By using the Historical-Critical Method and one definition of the concept of messianism and eschatology, we can observe many eschatological elements such as: hope for a day of glory and of salvation to Israel; one ideal davidic king with a new kingdom which surpasses the judahistic limits; action performed only by God, with his intervention in the history and the practice of justice; the relative end of history, with the clear distinction between two epochs and a new beginning; the aspect of definitivity and the deep relation with the history. Nevertheless, it's absent the future aspect, prevailing the past: thus, the text is not eschatological. Regarding to the messianism, despite the absence of messianic titles, Isaiah 8,23-9,6 expresses the hope of a radical modification from a historical and real character that ascends to the throne. Surely the boy described in the pericope is shown us as the ultimate fulfillment of the Immanuel's sign, and therefore a clearly messianic character.
\end{abstract}

Keywords: Book of the prophet Isaiah. Eschatology. Messianism.

\section{Introdução}

A perícope de Is 8,23-9,6 faz parte da liturgia da noite de Natal, em conexão com o anúncio efetuado em Lc 2,1-14, com ambos os textos depositando a esperança num personagem extraordinário, ${ }^{1}$ cujos paralelos favoreceram a interpretação clássica messiânica. ${ }^{2}$ Mas classificar esse texto como escatológico e messiânico depende de uma adequada conceituação desses termos, bem como situá-lo em sua época de composição. Inicia-se, portanto, a análise da perícope usando o Método Histórico-

\footnotetext{
${ }^{1}$ SIMIAN-YOFRE, H., Testi isaiani dell'avvento, p. 235-236.

${ }^{2}$ BEALE, G. K.; CARSON, D. A., Comentário do uso do Antigo Testamento no Novo Testamento, p. 335-336.
} 
Crítico, o qual busca "explicar todo texto a partir de seus pressupostos e entender sua intenção original".3 Segue-se a sequência tradução e segmentação / crítica textual / crítica da constituição do texto / crítica da forma / crítica do gênero literário e da redação / semântica do texto. ${ }^{4} \mathrm{~A}$ crítica da redação será colocada junto à crítica do gênero literário (e, consequentemente, após a crítica da forma) para aproveitar os elementos levantados anteriormente. ${ }^{5}$ Em razão das dificuldades encontradas neste texto, insere-se um comentário dessa tradução para explicitar termos e expressões ${ }^{6}$ De posse desses dados, efetua-se a análise de seu caráter escatológico e messiânico a partir de um conceito adequadamente definido.

\section{Análise de Is 8,23-9,6}

\subsection{Tradução e Segmentação}

\begin{tabular}{|c|c|c|}
\hline 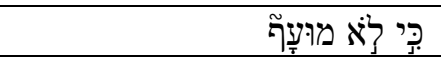 & $8,23 a$ & Contudo, não há escuridão \\
\hline 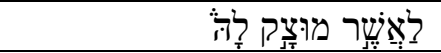 & $\mathbf{8 , 2 3 b}$ & para a que tem angústia! \\
\hline 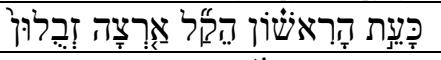 & $8,23 c$ & Como no primeiro tempo desprezou a terra de Zebulon \\
\hline 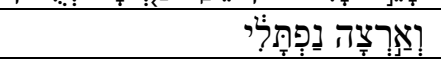 & 8,23d & e (desprezou) a terra de Naftali, \\
\hline 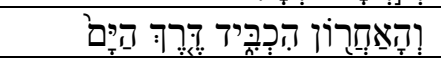 & $8,23 e$ & ao final honrou o caminho do mar, \\
\hline 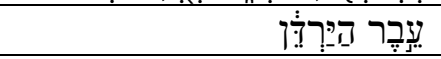 & $8,23 f$ & (honrou) o além-Jordão, \\
\hline 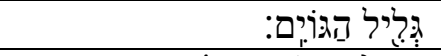 & $8,23 \mathrm{~g}$ & (honrou) a Galileia dos povos. \\
\hline 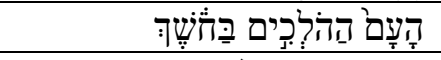 & 9,1a & O povo que andava em trevas \\
\hline 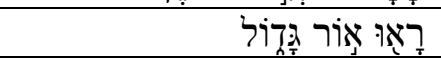 & 9,1b & viu uma grande luz, \\
\hline 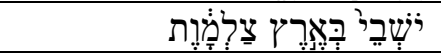 & $9,1 \mathrm{c}$ & aos que habitavam na terra de densa escuridão \\
\hline 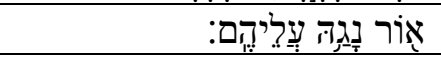 & 9,1d & uma luz raiou! \\
\hline 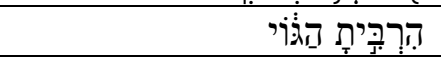 & 9,2a & Multiplicaste o povo, \\
\hline 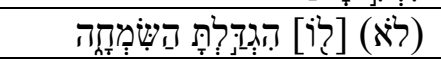 & $9,2 b$ & aumentaste-lhe a alegria; \\
\hline 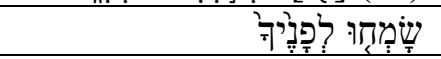 & $9,2 \mathrm{c}$ & alegraram-se diante de ti, \\
\hline 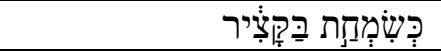 & 9,2d & (alegraram-se) como na alegria da ceifa, \\
\hline 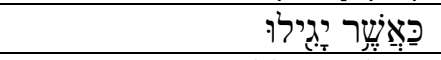 & $9,2 \mathrm{e}$ & como os que regozijam \\
\hline 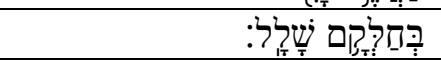 & $9,2 \mathrm{f}$ & quando é partilhado o despojo. \\
\hline 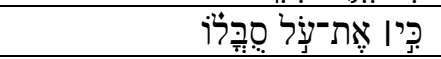 & 9,3a & Contudo, (despedaçou) o jugo de seu fardo, \\
\hline 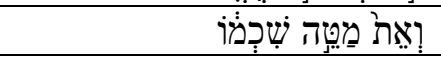 & $9,3 \mathbf{b}$ & (despedaçou) a vara de seus ombros, \\
\hline 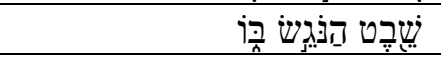 & $9,3 \mathrm{c}$ & (despedaçou) o bastão do que o oprimia, \\
\hline 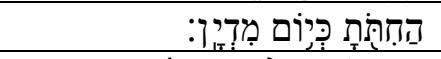 & 9,3d & despedaçou como no dia de Midiã. \\
\hline 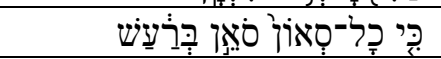 & 9,4a & Contudo, toda bota que pisa ruidosamente, \\
\hline 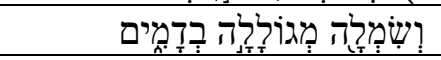 & $9,4 b$ & a veste empapada de sangue \\
\hline 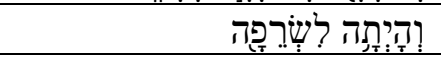 & $9,4 \mathrm{c}$ & serão para incineração, \\
\hline 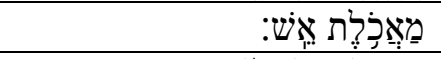 & 9,4d & (serão) alimento para o fogo. \\
\hline 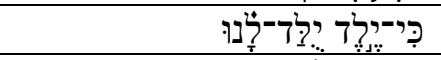 & $\mathbf{9 , 5 a}$ & Contudo, um menino nasceu para nós, \\
\hline 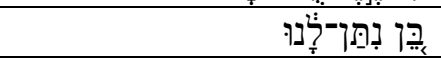 & $9,5 b$ & um filho foi dado para nós! \\
\hline 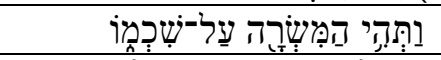 & $9,5 \mathrm{c}$ & Estará o domínio sobre seus ombros, \\
\hline 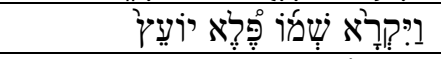 & 9,5d & alguém proclama seu nome: Milagre de Conselheiro, \\
\hline אַל גְּּוֹר & $9,5 \mathrm{e}$ & (proclama) Deus Herói, \\
\hline
\end{tabular}

\footnotetext{
${ }^{3}$ SIMIAN-YOFRE, H., Diacronia, p. 74-75. Salienta-se que não se anula a interpretação tradicional cristã: quando R. L. Saucy faz a pergunta se Cristo é o cumprimento das profecias do "Israel Nacional", sua resposta é "sim e não" (SAUCY, R. L., Is Christ the Fulfillment of National Israel's Prophecies?, p. 17).

${ }^{4}$ LIMA, M. L. C., Exegese Bíblica, p. 75-76.

${ }^{5}$ LIMA, M. L. C., Exegese Bíblica, p. 133-134.

${ }^{6}$ LIMA, M. L. C., Exegese Bíblica, p. 81.
} 


\begin{tabular}{|c|c|c|}
\hline אַבְיעַד & $\mathbf{9 , 5 f}$ & (proclama) Pai Eterno, \\
\hline 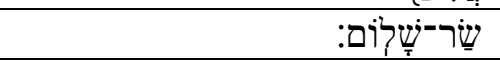 & $9,5 \mathrm{~g}$ & (proclama) Príncipe da Paz. \\
\hline 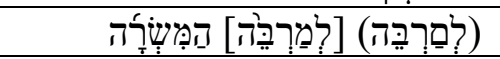 & $9,6 \mathbf{a}$ & Para que haja incremento do domínio \\
\hline 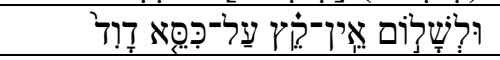 & $9,6 \mathbf{b}$ & e para que a paz não tenha fim sobre o trono de Davi \\
\hline 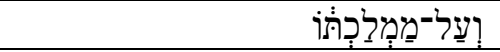 & $9,6 \mathrm{c}$ & e (para que haja paz) sobre seu reino; \\
\hline 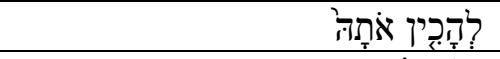 & 9,6d & para firmá-lo \\
\hline 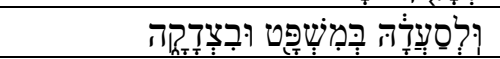 & $9,6 e$ & e para sustentá-lo mediante o juízo e a justiça. \\
\hline 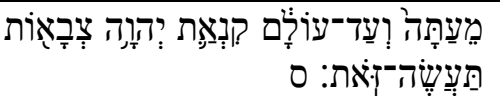 & $9, \mathbf{6 f}$ & $\begin{array}{l}\text { Desde agora e para sempre o zelo de YHWH dos } \\
\text { Exércitos faz isso! }\end{array}$ \\
\hline
\end{tabular}

\subsection{Comentário da Tradução}

8,23a: A partícula יכִ pode ser demonstrativa ou conjuntiva. ${ }^{7}$ Segue-se a sugestão de Watts ${ }^{8}$ ao traduzir por "nevertheless", assumindo o seu caráter conjuntivo e fazendo uma contraposição ao caráter sombrio do contexto anterior. O substantivo מוּעָ pode ser associado com a raiz II עוף "ser escuro", com a raiz II עיף "brilhar". "Vários autores concordam com a primeira opção e traduzem como "escuridão"."11

8,23c: A dificuldade aqui apontada por alguns autores encontra-se no fato de que עִ é uma palavra

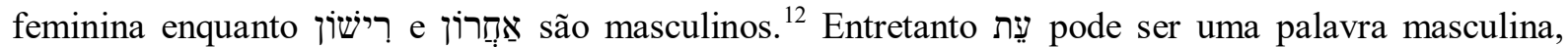
especialmente no hebraico tardio, como em Esd $10,14 .{ }^{13}$ Por isso pode ser compreendida no seu sentido

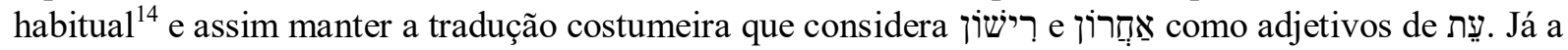
forma אַרְצָה deve ser entendida como uma forma de acusativo ou de locativo. ${ }^{15}$

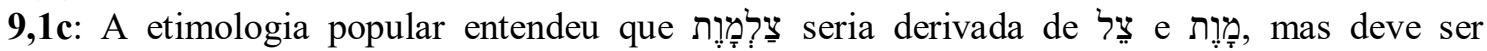
identificada com uma raiz II צלם relacionada a escuridão, trevas. ${ }^{16}$

9,2b: Texto dificílimo, sugerindo problemas de transmissão textual, o qual será analisado com maiores detalhes na crítica textual; mas segue-se aqui a proposta do qere do texto massorético: a leitura iל ao invés do ketiv לא, e colocando-o no segundo segmento. ${ }^{17}$

9,4a: Tanto o substantivo quanto o verbo provenientes da raiz סאן são hapax legomenona, sendo o verbo denominativo do substantivo. Na dificuldade de reproduzir em português essa aliteração, seguese a sugestão de Alonso-Schökel. ${ }^{18}$

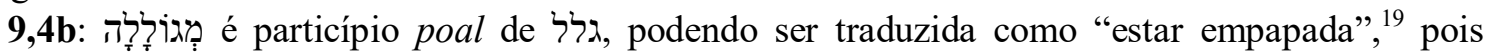
embora a raiz signifique "rolar", "revolver" 20 pode ser identificada além da raiz I com o significado tradicional uma raiz II significando "manchar", "estar sujo" - usada também em 2Sm 20,12 e Eclo $12,14 .^{21}$

\footnotetext{
${ }^{7}$ KOEHLER, L. et al., Hebrew and Aramaic Lexicon of the Old Testament, p. 470-471.

${ }^{8}$ WATTS, J. D. W., Isaiah 1-33, p. 167-168.

${ }^{9}$ BROWN, F., DRIVER, S. R.; BRIGGS, C. A., The Brown-Driver-Briggs Hebrew and English Lexicon, p. 734.

${ }^{10}$ KOEHLER, L. et al., עיף, p. 558.

${ }^{11}$ BLENKINSOPP, J., Isaiah 1-39, p. 245; ALONSO SCHÖKEL, L., עיף, p. 361; e WATTS, J. D. W., Isaiah 1-33, p. 167.

${ }^{12}$ WILDBERGER, H., A Continental Commentary, p. 384-385.

${ }^{13}$ BROWN, F., DRIVER, S. R.; BRIGGS, C. A., צֶ, p. 773.

${ }^{14}$ SIMIAN-YOFRE, H., Testi isaiani dell'avvento, p. 239.

${ }^{15}$ WATTS, J. D. W., Isaiah 1-33, p. 169.

16 KOEHLER, L. et al., צלם, p. 1028-1029.

${ }^{17}$ LANGE, J. P. et al., A Commentary on the Holy Scriptures, p. 140.

${ }^{18}$ ALONSO SCHÖKEL, L., סאן, p. 460.

${ }^{19}$ ALONSO SCHÖKEL, L., גלר, p. 140.

${ }^{20}$ BROWN, F., DRIVER, S. R.; BRIGGS, C. A., גלר, p. p. 164

${ }^{21}$ KOEHLER, L. et al., גלל, p. 193-194.
} 
9,5d: Ao contrário do que fazem algumas traduções, que se coloca o par como um único nome, e não dois. ${ }^{22}$

9,5f: Embora o texto massorético entenda aqui אִבְיעַ uma única palavra, devemos entender na verdade duas palavras a serem traduzidas. ${ }^{23}$

9,6a: Texto difícil, o qual será debatido mais detalhadamente na crítica textual. Usa-se uma única palavra, de acordo com o qere do texto massorético, a qual pode ser entendida como particípio hifil ${ }^{24}$ de רבה, ou como substantivo. ${ }^{25}$ Como esta palavra também aparece em Is 33,23 , Gray ${ }^{26}$ analisa,

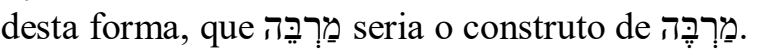

\subsection{Crítica Textual}

Este texto apresenta alguns sérios problemas de transmissão, que são até mesmo determinantes para a interpretação e visão geral da passagem.

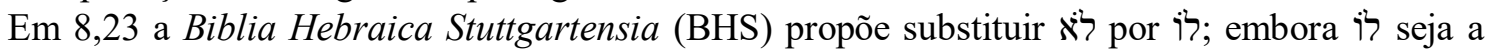
leitura encontrada em $1 \mathrm{QIs}^{\mathrm{a}}$, a leitura do texto massorético é apoiada pelos demais manuscritos, pela LXX, Vulgata, Peshitta e Targum. No lugar de מוּעָף do texto massorético temos מעופף em 1QIs, que remete ao particípio polel de עוף, "voar", leitura conhecida pela Vulgata (et non poterit avolare, "e não poderá voar"), mas que não é apoiada por nenhum outro manuscrito. ${ }^{27}$

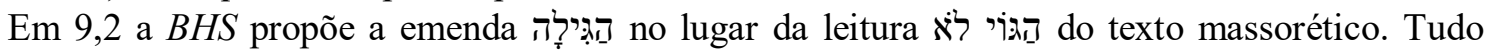
porque a tradição massorética transmitiu um qere divergente do ketiv: לל לא לא a emenda da $B H S$, entendendo que ela atende à métrica e ao paralelismo que é visto em toda a perícope, os quais seriam repentinamente quebrados com a leitura massorética. Assim entendem outros comentaristas, como Blenkinsopp, ${ }^{29}$ Gray $^{30}$ e Kaiser. ${ }^{31}$ Entretanto esta emenda "mutila" o texto massorético, pois envolve simultaneamente uma divisão da palavra e troca de letras. Além do mais, nenhum manuscrito ou versão antiga sai em defesa desta emenda. Claramente לא e o texto mais difícil, atestado até mesmo em $1 \mathrm{QIs}{ }^{\mathrm{a}}$ - sendo, portanto, o preferível. Mas quanto ao qere do texto massorético, confirmado na Peshitta e no Targum e adotada por comentaristas modernos como Lange, ${ }^{32}$ Oswalt $^{33} \mathrm{e}$ Young ${ }^{34}$ ? Esta insistência talvez indique que ללא לוא (ou mais especificamente, como em 1QIs ) seja uma forma antiga de iל: este mesmo tipo de intercâmbio é encontrado em outras 17 passagens - na maioria delas $^{35}$ claramente temos o sentido de לול, e as demais ${ }^{36}$ sugerem לא. Não podemos afirmar; por outro lado, a estatística apresentada demonstra no mínimo que o caso aqui apresentado no texto isaiano não é isolado. Pode-se levantar a hipótese de que os massoretas inserissem aqui este qere por influência dessas demais passagens. Ou, como sugere Gray, "provavelmente é uma antiga emenda conjectural que restaura

\footnotetext{
${ }^{22}$ KOEHLER, L. et al.,

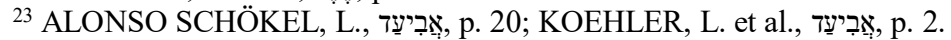

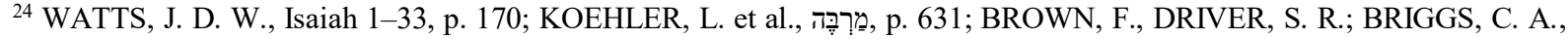

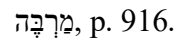

${ }^{25}$ ALONSO-SCHÖKEL, L., מִּרֶ, p. 401.

${ }^{26}$ GRAY, G. B., A Critical and Exegetical Commentary on the Book of Isaiah, p. 176.

${ }^{27}$ Para todas as menções de 1QIs ${ }^{\mathrm{a}}$ : LEXHAM PRESS, 1Q Isaiah a. Base de dados no Software Bíblico Logos, Versão 7.

${ }^{28}$ WATTS, J. D. W., Isaiah 1-33, p. 169.

${ }^{29}$ BLENKINSOPP, J., Isaiah 1-39, p. 246.

${ }^{30}$ GRAY, G. B., A Critical and Exegetical Commentary on the Book of Isaiah, p. 169.

${ }^{31}$ KAISER, O., Isaiah 1-12, p. 203.

${ }^{32}$ LANGE, J. P. et al., A Commentary on the Holy Scriptures, p. 140.

${ }^{33}$ OSWALT, J., Comentários do Antigo Testamento, p. 299.

${ }^{34}$ YOUNG, E., The Book of Isaiah, p. 325-326.

${ }^{35} 10$ ocorrências: Êx 21,8; Lv 11,21; 25,30; $1 \mathrm{Sm}$ 2,3; 2Sm 16,18; 2Rs 8,10; 1Cr 11,20; Esd 4,2; Sl 100,3 e Is 49,5 (base de dados em Software Bible Works for Windows, Version 10).

367 ocorrências: Jó 6,21; 13,15; 41,4; Sl 139,16; Pv 19,7; 26,2; Is 63,9 (base de dados no Software Bible Works for Windows, Version 10).
} 
sentido a expensas do estilo e sem restaurar o paralelismo". ${ }^{37}$ Uma escolha difícil; entretanto, aceitamos o qere dos massoretas, e a argumentação do comentário de Lange, ${ }^{38}$ como já sinalizamos supra ao comentar a tradução. Young ainda acrescenta: "ademais, esta seria dupla menção ao incremento da alegria sem nenhuma menção ao incremento do povo. Parece melhor ler lô no lugar do similar sonoro negativo". 39

Em 9,5 temos אִ ְִבְע como uma única palavra, mas claramente deve ser entendido como duas palavras. ${ }^{40}$ Somente 1 QIs ${ }^{\mathrm{a}}$ traz textualmente como duas palavras, e embora não descartemos uma fusão em data muito remota, exceto por este manuscrito nenhum outro apoia essa leitura. Isso faz de אִ a leitura mais difícil, e assim a preferida.

Finalmente, em 9,6 o problema envolvido é o uso do final no meio da palavra: לִסִרְֶָ. O aparato crítico da $B H S$ faz as seguintes propostas para explicar esta anomalia: 1) seria a junção acidental de

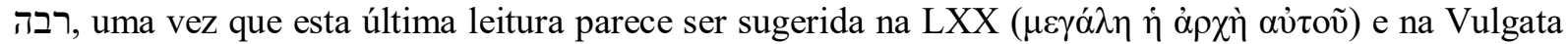
(multiplicabitur eius imperium) considerando ל̧ ą ao invés de לם 2 ; 2) uma ditografia da parte final da

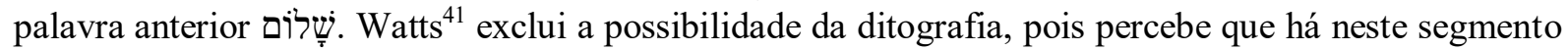
uma aliteração envolvendo a letra $ל$. Em defesa da unicidade da palavra proposta pelo texto massorético

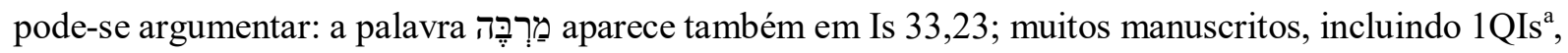

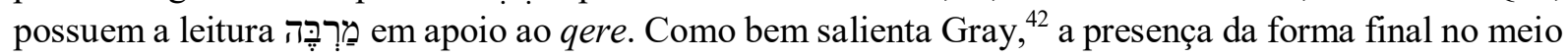
da palavra aponta para uma corrupção textual ou ambiguidade. Talvez tenha ocorrido o oposto sugerido por alguns: bem cedo (por estar insinuada na LXX) houve uma separação em duas palavras, a qual teria sido então corrigida pelo texto massorético.

\subsection{Crítica da Constituição do Texto}

A delimitação do final dessa passagem fica bem definida no v. 6, uma vez que presencia-se aqui um contexto de libertação, enquanto a partir do v. 7 o contexto é de ira. Entretanto, onde começar: considerando integralmente $8,23,{ }^{43}$ apenas a partir de $8,23 \mathrm{c}^{44}$ ou a partir de $9,1 ?^{45}$

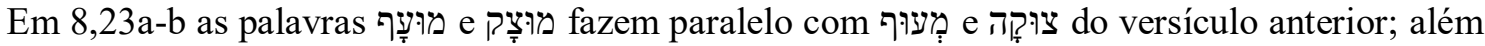

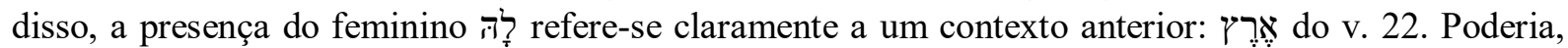
assim, incluir-se 8,23a-b no contexto de 8,21a-23b, o qual Sicre Diaz e Alonso-Schökel denominam de "dias obscuros". ${ }^{46}$ Mas deve-se observar a partícula ’ִ̣: se no v. 21 possui um sentido temporal, aqui há o sentido conclusivo/adversativo que continuará em 9,3-5. Além disso, aceitando a tradução "escuridão" para מוּעָ em 8,23a nota-se já o tema positivo da libertação que continuará em 9,1 e em toda a perícope. Entende-se que esses fatos, conforme analisados, possibilitam a inclusão de 8,23a-b na perícope. Gray mostra que 8,23a-b pode ser uma glosa explicativa: "não é מוּעָ usada (metaforicamente) sobre a pessoa que está em angústia?". ${ }^{47}$ Conclui-se que 8,23a-b funciona como um "gancho", tanto ligado ao contexto anterior quanto ao posterior. Sweeney, ${ }^{48}$ mesmo mostrando que o contexto na verdade começaria em 8,16 , concorda que $8,23-9,6$ forma uma subunidade.

\footnotetext{
${ }^{37}$ GRAY, G. B., A Critical and Exegetical Commentary on the Book of Isaiah, p. 169.

${ }^{38}$ LANGE, J. P. et al., A Commentary on the Holy Scriptures, p. 140.

${ }^{39}$ YOUNG, E., The Book of Isaiah, p. 326.

${ }^{40}$ Comentário da tradução.

${ }^{41}$ WATTS, J. D. W., Isaiah 1-33, p. 170.

${ }^{42}$ GRAY, G. B., A Critical and Exegetical Commentary on the Book of Isaiah, p. 176.

${ }^{43}$ BLENKINSOPP, J., Isaiah 1-39, p. 245-246; WATTS, J. D. W., Isaiah 1-33, p. 167-168.

${ }^{44}$ KAISER, O., Isaiah 1-12, p. 203-204.

${ }^{45}$ OSWALT, J., Comentários do Antigo Testamento, p. 299-300.

${ }^{46}$ ALONSO-SCHÖKEL, L.; SICRE DIAZ, J. L., Profetas I, p. 157-158.

${ }^{47}$ GRAY, G. B., A Critical and Exegetical Commentary on the Book of Isaiah, p. 163.

${ }^{48}$ SWEENEY, M., Isaiah 1-39, p. 175 passim.
} 


\subsection{Crítica da Forma}

Numa análise lexicográfica preliminar, o que sobressalta é a incidência da partícula ’̣̣, a qual aparece 4 vezes, formando como que 4 seções. Ao dividir em "blocos" sintáticos, percebe-se a seguinte disposição:

V. 8,23a-b: Estes primeiros segmentos, duas proposições nominais simples, ${ }^{49}$ como visto na crítica da constituição do texto, possuem vocábulos da perícope anterior, fazendo uma "ponte" e servindo assim de introdução para essa nova perícope aqui abordada.

V. 8,23c-g: Neste bloco de sequência $p$ - $x$-qatal/w-x-qatal $(2 \mathrm{x}) /$ qatal $(2 \mathrm{x})^{50}$ o campo semântico é dominado por termos relacionados ao Reino do Norte: a menção de duas tribos (Zebulon e Naftali) e três regiões (o caminho do mar, além-Jordão e Galileia). Com relação à estilística, há um paralelismo

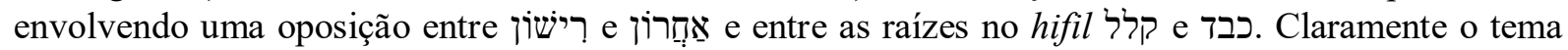
aqui é glória após humilhação.

V. 9,1a-d: Neste bloco de dupla sequência $\mathrm{ON} / x$-qatal, o campo semântico inclui a contraposição

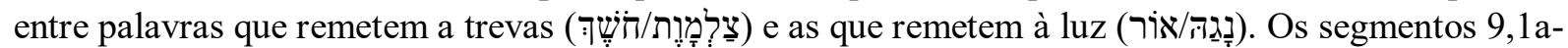
b estão em paralelismo perfeito com os segmentos 9,1c-d de acordo com o padrão a-b-a'-b'. Se no bloco anterior as raízes estavam no hifil, aqui estão no paal/qal. Tema: a luz após as trevas.

V. 9,2a-f: Percebe-se aqui dois pares de raízes em paralelismo, duas no hifil (גדל e רבה e (גדל), e outras duas no paal (גיל e (גמה), repetindo a sequência vista anteriormente (hifil no segundo bloco e paal no

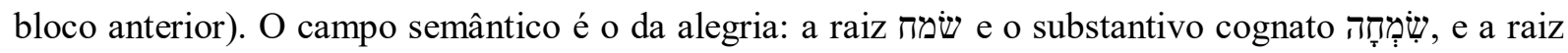
גיל O tema envolve tanto a ideia de abundância (através das raízes גדל e רבה) quanto a de alegria portanto, uma "alegria abundante".

V. (9,3): Este bloco é dominado por uma única raiz verbal flexionada, "revelada" apenas no segmento final, mas já implícita nos três segmentos anteriores - e novamente no hifil,

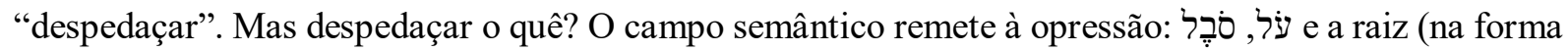
participial) נגש.

V. 9,4a-b: Estes dois segmentos envolvendo proposições nominais simples com raízes na forma participial formam um paralelismo envolvendo um padrão substantivo - particípio - preposição ?̦̣ substantivo. O segmento 9,4 envolve uma aliteração com os cognatos da raiz סאן, que proporciona a onomatopeia das botas pisando "ruidosamente". ${ }^{51}$

V. 9,4c-d: Tem-se aqui os dois únicos segmentos em weqatal em toda a perícope, formando um

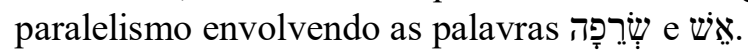

V. 9,5a-b: Dois segmentos em paralelismo, envolvendo uma rima com a palavra רָּ; o primeiro segmento envolve uma aliteração com a letra ל, e novamente uma onomatopeia - desta vez do choro do bebê. É o anúncio do nascimento do bebê.

V. 9,5c-g: Neste bloco aparecem os únicos segmentos com wayyiqtol, não o típico da narração, mas o que dá continuidade a um segmento em $x$-qatal anterior ("wayyiqtol consecutivo" ${ }^{, 52}$ ). Predominam os nomes dados ao bebê que nasceu. Tema: o anúncio dos nomes.

V. 9,6a-e: Este bloco tem uma predominância maciça da preposição ?̧, formando uma aliteração;

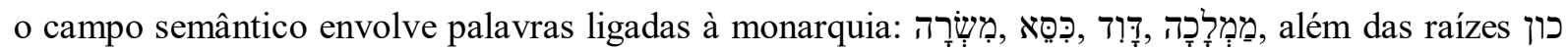
(no hifil) e סעד. Com essas raízes (significando "firmar" e "sustentar"), o tema aqui é "o estabelecimento do reino".

\footnotetext{
${ }^{49}$ Segue-se a classificação proposta por Niccacci: uma proposição verbal é aquela que começa com um verbo, enquanto a nominal começa com substantivo. Se a este se segue uma forma verbal conjugada, tem-se uma nominal complexa (NICCACCI, A., Sintaxis del Hebreo Biblico, p. 27).

${ }^{50}$ Seguindo a nomenclatura de Niccacci, na qual "x" indica o substantivo como o elemento ocupando a primeira posição dentro de uma oração; 0 indica que não há substantivo iniciando essa oração. As siglas $\mathrm{N}$, w e p indicam que a oração inicia respectivamente ou pela partícula negativa לא, ou pelo I que não pertence à conjugação do verbo, ou por uma preposição qualquer (NICCACCI, A., Sintaxis del Hebreo Biblico, p. 29-31).

${ }^{51}$ WATSON, W. G. E., Classical Hebrew Poetry, p. 228.

${ }^{52}$ NICCACCI, A., Sintaxis del Hebreo Bíblico, p. 161.
} 
V. 9,6f: Este último bloco, com o único segmento em yiqtol de toda a perícope, forma como que uma conclusão de todo o conjunto.

Em 8,23a-9,2f, como bem observam Alonso-Schökel e Sicre Diaz, ${ }^{53}$ perpassa a temática da salvação. Após a introdução em $8,23 \mathrm{a}-\mathrm{b}$ há três motivos de salvação: glória após a humilhação $(8,23 \mathrm{c}-$ g), luz após trevas $(9,1)$ e alegria abundante $(9,2)$. Após o tema do fim da opressão em 9,3 temos em 9,4

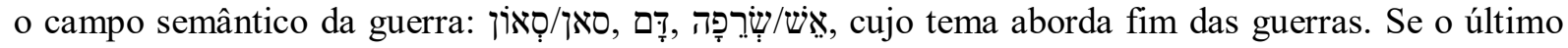
bloco é conclusivo, os três blocos englobando 9,5a-6e formam um tríplice anúncio real: do seu nascimento, dos seus nomes e do estabelecimento de seu reino.

Em suma, a estrutura da perícope, onde se vê uma estrutura concêntrica a-b-b'-a':

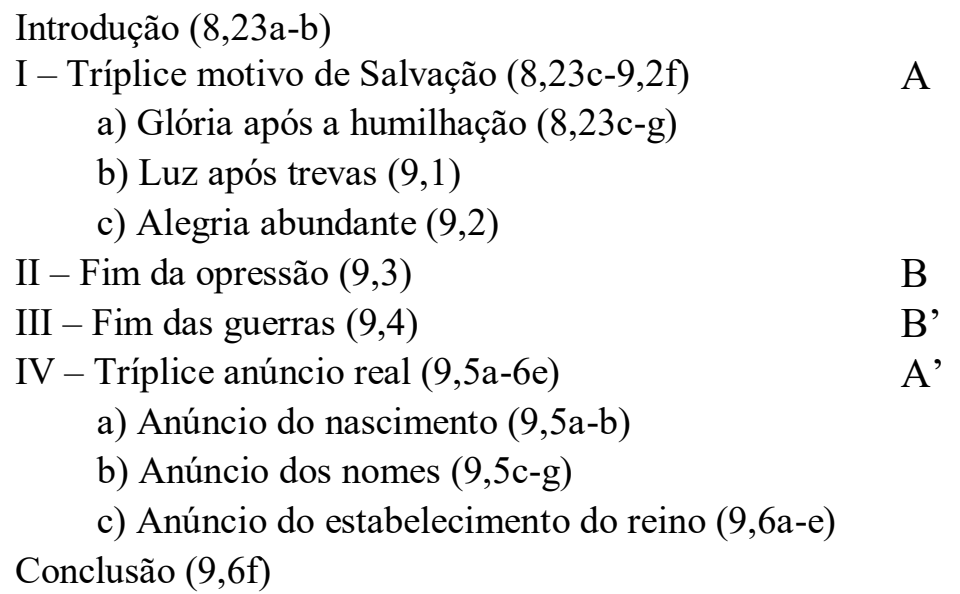

\subsection{Crítica do Gênero Literário e da Redação}

Quando discute-se o gênero literário, o texto de Is 8,23-9,6 pode ser considerado simplesmente como um oráculo de salvação $;{ }^{54}$ mas também são levantadas outras hipóteses. Sweeney analisa essa passagem como parte integrante de um grande bloco que começa em 8,16 e classifica de modo genérico como instrução profética; depois, particulariza 8,23-9,6 como um salmo real de ação de graças, o qual celebra a entronização de um novo monarca davídico. ${ }^{55}$ Segundo Mowinckel ${ }^{56}$ é simplesmente um hino de ação de graças, um "canto de ação de graças" de acordo com Sicre Diaz, ${ }^{57}$ enquanto Kaiser especifica aqui um hino profético de ação de graças. ${ }^{58}$

Sendo um salmo celebrando uma entronização, quem seria este novo monarca? Isto leva inevitavelmente à data de composição, e consequentemente à autenticidade isaiana do oráculo. Pode-se então dividir em duas opiniões básicas: a de que pertence de fato ao grande profeta do século VIII a.C.; e a de que vem do exílio ou do pós-exílio.

Os defensores da primeira hipótese afirmam que esta profecia foi dada como um memorial sobre a guerra siro-efraimita, ou ainda não muito tempo depois, talvez por ocasião do nascimento de Ezequias. ${ }^{59}$ Crook $^{60}$ faz uma análise da possibilidade de que Amós e Miqueias conheceram não somente 9,2-7 como também 11,1-9, e conclui que evidentemente ambas as passagens pertencem ao final do século VIII a.C., e, portanto, esse dado depõe a favor da autoria isaiana ${ }^{61}$ Carlson mostra que o caráter

\footnotetext{
${ }^{53}$ ALONSO-SCHÖKEL, L.; SICRE DIAZ, J. L., Profetas I, p. 158-159.

${ }^{54}$ LIMA, M. L. C., Mensageiros de Deus, p. 104-105.

${ }^{55}$ SWEENEY, M., Isaiah 1-39, p. 179-180.

${ }^{56}$ MOWINCKEL, S., He That Cometh, p. 102.

${ }^{57}$ SICRE DIAZ, J. L., Introdução ao profetismo bíblico, p. 429.

${ }^{58}$ KAISER, O., Isaiah 1-12, p. 207.

${ }^{59}$ KAISER, O., Isaiah 1-12, p. 215.

${ }^{60}$ CROOK, M. B., Did Amos and Micah Know Isaiah 9,2-7 and 11,1-9?, p. 144 passim.

${ }^{61}$ CROOK, M. B., Did Amos and Micah Know Isaiah 9,2-7 and 11,1-9?, p. 151.
} 
anti-assírio da perícope evidencia a "conviç̧ão de Isaías de que a futura política de Judá está indissoluvelmente atada à dinastia de Davi", mostrando que juntamente com 11,1- 9 "não somente são autênticos, como também fortes expressões da garantia básica feita em Is. VII" ${ }^{62}$ Von Rad da mesma forma entende que esse oráculo se encaixa perfeitamente no quadro profético isaiano, ${ }^{63}$ e Simian-Yofre não vê razão para negar a paternidade isaiana devido ao vocabulário típico utilizado pelo profeta. ${ }^{64}$ Rignell declara que "estamos lidando aqui com as genuínas palavras do profeta Isaías, estampada com sua personalidade inspirada". ${ }^{5}$

Para o segundo grupo, Young diz que alguns comentaristas mostram o desconhecimento de Jeremias, Ezequiel e o Dêutero-Isaías acerca dessa profecia, embora pessoalmente defenda a autoria isaiana ${ }^{66}$ Kaiser defende que temos aqui uma teologia profética pós-exílica com preocupações querigmáticas, e a situa mais precisamente entre o final do sexto e meados do quinto século, evidenciando esperanças escatológicas. ${ }^{67}$ Watts vê aqui uma eclosão nostálgica de fervor patriótico, a esperança da "inauguração de uma segunda era de paz e prosperidade como a de Davi e Salomão". Mais à frente, entende que este oráculo encontra lugar no século quinto, no período persa ${ }^{68}$ Gray concorda com a conexão com Is 11 e afirma que se essa última passagem é exílica ou pós-exílica, o mesmo pode ser concluído para nossa perícope. ${ }^{69}$

Lendo atentamente o texto "sem pensar na tradicional interpretação cristã, a impressão imediata que temos é sem dúvida de que ele descreve algo que já aconteceu". ${ }^{70}$ Se a raiz constitui de fato um aramaísmo, seria mais um fator a depor pelo aspecto tardio da passagem $;{ }^{71}$ e como visto acima na tradução, se עy realmente for uma palavra masculina aqui, isto é típico do hebraico tardio. Sicre Diaz resolve dessa forma essa difícil equação: "a libertação do jugo assírio, o fim da guerra, a estabilidade da dinastia davídica - com pretensões, inclusive, aos territórios do Norte - nos projetam inevitavelmente na época de Josias (640-609), um século depois de Isaías". ${ }^{72}$

\section{Semântica do Texto}

Sweeney coloca esta perícope dentro do contexto maior que começa em 8,16 no qual demonstra que aqueles que não se firmam nem na Torah nem no testemunho estarão em trevas. ${ }^{73}$ Logo na introdução, de repente, os lamentos expressos em 8,19-22 são interrompidos por clamores de esperança; nega-se que angústia e trevas sejam resultados inevitáveis dos eventos até então expressos. Contradizse a mensagem dada anteriormente em 6,11-21; 7,8 e 8,7; muda-se o plano divino outrora anunciado em 2,6-9, concede-se graça apesar da apostasia manifestada em 1,2-8. ${ }^{74} \mathrm{O}$ uso do feminino $(8,23 \mathrm{a}-\mathrm{b})$ pode ser referência ou à mãe mencionada no contexto anterior em 7,14 ou à Judá/Jerusalém num período crítico de sua história, e não necessariamente ao período pós-exílico; ${ }^{75}$ mas o contexto fica melhor explicado como referência à terra em angústia, com a sequência listando os motivos para que este estado não mais perdure.

Essa angústia cessará primeiramente mediante o tríplice motivo de salvação na primeira seção após a introdução $(8,23 \mathrm{c}-9,2 \mathrm{f})$. O povo descrito no v. 1 certamente é o mesmo de $8,23 .{ }^{76}$ Claramente há

\footnotetext{
${ }^{62}$ CARLSON, R. A., The Anti-Assyrian Character of the Oracle in Is. ix 1-6, p. 130.

${ }^{63}$ VON RAD, G., Teologia do Antigo Testamento, p. 597.

${ }^{64}$ SIMIAN-YOFRE, H., Testi isaiani dell'avvento, p. 232.

${ }^{65}$ RIGNELL, L. G., A Study of Isaiah 9:2-7, p. 31.

${ }^{66}$ YOUNG, E., The Book of Isaiah, p. 346.

${ }^{67}$ KAISER, O., Isaiah 1-12, p. 217.

${ }^{68}$ WATTS, J. D. W., Isaiah 1-33, p. 171-174.

${ }^{69}$ GRAY, G. B., A Critical and Exegetical Commentary on the Book of Isaiah, p. 166.

${ }^{70}$ MOWINCKEL, S., He That Cometh, p. 109.

${ }^{71}$ GRAY, G. B., A Critical and Exegetical Commentary on the Book of Isaiah, p. 166.

${ }^{72}$ SICRE DIAZ, J. L., Introdução ao profetismo bíblico, p. 429.

${ }^{73}$ SWEENEY, M., Isaiah 1-39, p. 178.

${ }^{74}$ WATTS, J. D. W., Isaiah 1-33, p. 171-174.

${ }^{75}$ BLENKINSOPP, J., Isaiah 1-39, p. 247.

${ }^{76}$ LANGE, J. P. et al., A Commentary on the Holy Scriptures, p. 141.
} 
uma alusão em 8,23 à anexação dos territórios do nordeste israelita por Tiglate-Pileser III em 732 a.C. a qual é descrita em 2 Rs 15,29, ${ }^{77}$ especialmente na menção do "primeiro tempo", embora Blenkinsopp o situe no "último tempo" e deixe a primeira menção para Hazael ou Ben-Hadad III, enquanto comentaristas antigos como Calvino e Ibn Ezra prefiram ver aqui pela ordem Tiglate-Pileser III e Salmanaser V. ${ }^{78}$ Seja como for, parece ser uma oportunidade para a casa de Davi reafirmar seu domínio sobre o remanescente do Reino de Israel. ${ }^{79}$ Esta é a luz que brilhou para os que outrora estavam em trevas. É a glória após a humilhação. E no v. 2, com o alargamento do povo, a alegria é aumentada ${ }^{80} \mathrm{~A}$ nação, novamente numerosa, tem grande alegria ${ }^{81}$ Um evento tão decisivo somente poderia ser trazido pelo próprio $\mathrm{YHWH} .{ }^{82}$

Convergindo para o centro, temos duas seções em paralelo com o tema acerca do fim. No v. 3, o "dia de Midiã" é uma referência à libertação operada por Deus através de Gedeão e apenas mais 300 homens contra um exército poderoso. O autor sagrado deseja mostrar que Deus pode levar a vitórias mesmo em situações que pareçam impossíveis. ${ }^{83}$ É a doutrina profética da libertação operada não por meios humanos, e sim por YHWH. ${ }^{84}$ Assim, Oswalt comenta que "por isso o profeta faz alusão àqueles eventos como evidência de que o quadro que ele ora projeta é inteiramente viável, em vista do caráter e poder de seu Deus" ${ }^{85}$ A opressão assíria é comparada ao do faraó no Êxodo, pelo uso da expressão ainda que num sentido ainda mais profundo ${ }^{86}$ Oswalt prossegue: "aqui Isaías vislumbra o dia em que Alguém mais poderoso que os assírios deste mundo fará os jugos em pedaços" ${ }^{87}$ No v. 4 percebe-se que se descreve uma guerra santa, a qual terminará quando todas as botas e uniformes militares forem queimados. ${ }^{88} \mathrm{O}$ horizonte escatológico da abolição da guerra é um tema sensível na tradição isaiana, como bem salienta Blenkinsopp. ${ }^{89}$ Não há como haver fim da opressão sem o fim das guerras.

Na quarta seção, no v. 5 há finalmente a descrição do nascimento de um herdeiro davídico, sobre quem se coloca esperanças de restauração do poder e glória da Casa de Davi, como era na época do reinado unido de Davi e Salomão. ${ }^{90} \mathrm{O}$ uso do wayyiqtol mas que possivelmente já tenha ocorrido. ${ }^{91} \mathrm{O}$ recém-nascido, apesar de não ser chamado de rei, possui atributos reais, pois existe todo um campo semântico relacionado, como já visto anteriormente. ${ }^{92} \mathrm{Se} e m$ Is 3,4 a presença de crianças como príncipes era um castigo, esta maldição agora é revertida por esta criança herdeira sobre a qual reside toda a responsabilidade governamental $;{ }^{93}$ "a culminação do uso que Isaías faz de meninos para indicar o senhorio providente de Deus sobre a história". ${ }^{94}$

Este menino é descrito com quatro nomes, e não cinco como vemos em algumas traduções, e Young apresenta quatro motivos para tal: se os dois últimos nomes são pares, assim também os primeiros; a acentuação massorética; a obtenção de uma notável simetria com os quatro nomes; e a

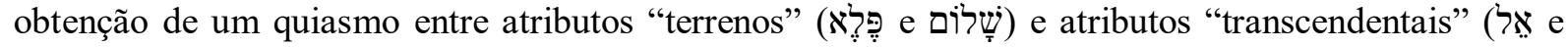
עֵ). ${ }^{95}$ São nomes com uma aura divina como verificado no protocolo egípcio, provavelmente mantido

\footnotetext{
${ }^{77}$ SWEENEY, M., Isaiah 1-39, p. 182; WATTS, J. D. W., Isaiah 1-33, p. 172.

${ }^{78}$ BLENKINSOPP, J., Isaiah 1-39, p. 247.

${ }^{79}$ SWEENEY, M., Isaiah 1-39, p. 178.

${ }^{80}$ YOUNG, E., The Book of Isaiah, p. 326.

${ }^{81}$ LANGE, J. P. et al., A Commentary on the Holy Scriptures: Isaiah, p. 141.

${ }^{82}$ KAISER, O., Isaiah 1-12, p. 209.

${ }^{83}$ WATTS, J. D. W., Isaiah 1-33, p. 173.

${ }^{84}$ GRAY, G. B., A Critical and Exegetical Commentary on the Book of Isaiah, p. 170.

${ }^{85}$ OSWALT, J., Comentários do Antigo Testamento, p. 303.

${ }^{86}$ YOUNG, E., The Book of Isaiah, p. 327.

${ }^{87}$ OSWALT, J., Comentários do Antigo Testamento, p. 303.

${ }^{88}$ WATTS, J. D. W., Isaiah 1-33, p. 173.

${ }^{89}$ BLENKINSOPP, J., Isaiah 1-39, p. 250.

${ }^{90}$ WATTS, J. D. W., Isaiah 1-33, p. 173.

${ }^{91}$ WILDBERGER, H., A Continental Commentary, p. 399.

92 OSWALT, J., Comentários do Antigo Testamento, p. 304.

${ }^{93}$ YOUNG, E., The Book of Isaiah, p. 330-331.

${ }^{94}$ OSWALT, J., Comentários do Antigo Testamento, p. 300.

${ }^{95}$ YOUNG, E., The Book of Isaiah, p. 333.
} 
no ritual judaíta, evitando, porém, o nome quíntuplo, ${ }^{96}$ expressando aspectos importantes de um governo e política ideais. ${ }^{97}$

Para uma tentativa de encontrar um personagem histórico que corresponda a esse menino, o rei Ezequias mantém a vantagem de harmonizar com o material precedente, incluindo o nascimento de Emanuel. ${ }^{98}$ Assim também pensa Sweeney ${ }^{99}$ e assim pensaram intérpretes medievais como Rashi e Ibn Ezra ${ }^{100}$ mas essa suposição tem sido abandonada, como bem salienta Gray. ${ }^{101}$ Sicre Diaz prefere entender que este menino é o rei Josias, sendo este poema composto então por ocasião da sua entronização, ${ }^{102}$ a qual foi efetuada quando ainda era um menino. Ele seria o que por último engrandeceu a área há muito tempo humilhada pelos assírios, integrando-a em um império davídico restaurado. Seria este o incremento do domínio. Sicre Diaz ainda comenta que "não causaria estranheza que a entronização oficial dele, ao atingir a maioridade, se celebrasse com especial entusiasmo". ${ }^{103}$

$\mathrm{Na}$ conclusão, o episódio chega ao clímax com a fervente oração de que o "zelo de YHWH dos Exércitos faz isso", ${ }^{104}$ expressão que constitui um hápax legomenon no texto bíblico, aparecendo somente outra vez em Is 37,32. Como bem salienta Oswalt, "Isaías reconhece que o quadro que tem pintado não será concretizado no curso das atividades corriqueiras. Só acontecerá por causa do amoroso envolvimento de Deus com seu povo". ${ }^{105}$

\section{Análise de seu Caráter Escatológico e Messiânico}

De origem "não muito clara", o termo "escatologia" etimologicamente está relacionado a ह̌ $\sigma \chi \alpha \tau o \varsigma$ - ou seja, o discurso sobre o "fim". ${ }^{106}$ Surge então a dificuldade de aplicação ao âmbito do Antigo Testamento, seja por não apresentar um ensino sistemático, seja pela ausência de uma clara referência ao final da história e do mundo. ${ }^{107}$ Consequentemente, os diversos estudiosos se dividiram entre rejeitar ou aceitar a escatologia no profetismo "clássico"; admiti-la no exílio ou pós-exílio, ou apenas na apocalíptica; e assim por diante. ${ }^{108}$

Dentre estes, Vriezen, na sua identificação dos períodos escatológicos, entende Isaías pertencendo ao período "proto-escatológico". Neste "a esperança se alarga com a ideia de um novo reino que ultrapassa os limites nacionais de Israel e para cuja instauração a ação de Deus surge como decisiva". É um passo adiante em relação ao período anterior, quando "espera-se um dia da salvação e glória para Israel, nos moldes da idealização do reinado davídico e que diz respeito a esperanças de caráter políticonacional". ${ }^{109}$ Todos esses elementos estão presentes na perícope: espera-se o dia de glória (mudança das trevas para a luz) e de salvação de Israel (fim da opressão e das guerras); um rei davídico ideal com um novo reino que ultrapassa os limites judaítas, reintegrando áreas do reino do Norte ("multiplicaste o povo"); ação efetuada somente por Deus (o "zelo de YHWH dos Exércitos faz isso!").

Outros elementos coletados de diversos estudiosos apontariam o caráter escatológico dessa passagem: ${ }^{110}$ há o fim relativo da história (indicado pelo fim das opressões e das guerras); um novo início (através de um rei davídico ideal, com um governo sem fim); a distinção clara de duas épocas

\footnotetext{
${ }^{96}$ KAISER, O., Isaiah 1-12, p. 212-213. Para um debate mais atual, OCKINGA, B., Hatshepsut's Appointment as Crown Prince and the Egyptian Background to Isaiah 9:5, p. 252-267.

${ }^{97}$ BLENKINSOPP, J., Isaiah 1-39, p. 250.

${ }^{98}$ BLENKINSOPP, J., Isaiah 1-39, p. 249.

${ }^{99}$ SWEENEY, M., Isaiah 1-39, p. 182.

${ }^{100}$ GRAY, G. B., A Critical and Exegetical Commentary on the Book of Isaiah, p. 172.

${ }^{101}$ GRAY, G. B., A Critical and Exegetical Commentary on the Book of Isaiah, p. 165-166.

${ }^{102}$ Crítica da Redação supra.

${ }^{103}$ SICRE DIAZ, J. L., Introdução ao profetismo bíblico, p. 429-431.

${ }^{104}$ WATTS, J. D. W., Isaiah 1-33, p. 174.

105 OSWALT, J., Comentários do Antigo Testamento, p. 308.

${ }^{106}$ LIMA, M. L. C., Salvação entre juízo, conversão e graça, p. 15.

${ }^{107}$ LIMA, M. L. C., Salvação entre juízo, conversão e graça, p. 16

${ }^{108}$ LIMA, M. L. C., Salvação entre juízo, conversão e graça, p. 16-44.

${ }^{109}$ LIMA, M. L. C., Salvação entre juízo, conversão e graça, p. 33.

${ }^{110}$ Detalhados em LIMA, M. L. C., Salvação entre juízo, conversão e graça, p. 46-47.
} 
(época de trevas, opressão e guerras em contraposição à época de luz, liberdade e paz); intervenção de Deus na história ("o zelo de YHWH dos Exércitos faz isso"); o juízo de Deus (representado tanto pela quebra do jugo quanto pela incineração das vestes militares); o aspecto da definitividade (paz sem fim, desde agora e para sempre); e a profunda relação com a história (a comparação com a opressão do faraó no Exxodo e a libertação dos madianitas operada por Gedeão). Isto fica ainda mais claro quando analisamos o "núcleo do conceito": ${ }^{111}$ ainda que não tenhamos aqui expressões do tipo "no final dos tempos", existe uma "referência a um tempo futuro, apresentado como a entrada em uma situação definitiva, permanente" ("e para que a paz não tenha fim sobre o trono de Davi"); uma "descontinuidade histórica grande, uma ruptura fortemente marcada" ("toda bota que pisa ruidosamente, a veste empapada de sangue serão para incineração"); e a centralidade de Israel ("multiplicaste o povo"). Albares Martin completa: "é quando a situação se modifica radicalmente com o tom exultante de Is 9,1-6". ${ }^{112}$ Entretanto, falta o aspecto futuro: o texto aponta para algo que já ocorreu, predomina o passado, as poucas passagens no futuro falam de um futuro "próximo". Portanto, o texto não é escatológico.

Embora não escatológico, não podemos descartar o caráter messiânico do rei anunciado apenas

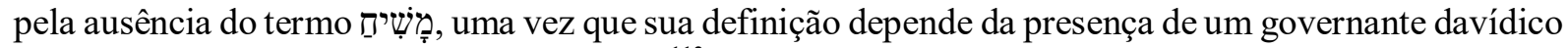
futuro, o qual encontra-se nessa passagem. ${ }^{113}$ Segundo Albares Martin, embora "messianismo seria a concepção bíblica que atribui ao representante da monarquia israelita uma função particular na gestão do reino - e na tutela de seu povo", Is 8,21-9,6 expressa a esperança de uma modificação radical "a partir do momento em que um personagem histórico e concreto, a saber um herdeiro real e não uma figura mítica e escatológica, ascenda ao trono". ${ }^{114}$

O contexto imediato parece não pertencer a predições messiânicas; ${ }^{115}$ no entanto, deve-se observar uma incrível aura transcendental que ronda esse personagem. ${ }^{116}$ Um rei ser designado como o próprio Deus, somente em S1 45,7 - talvez por influência egípcia. ${ }^{117}$ Há, indubitavelmente, um caráter extraordinário nesse governante, no qual "ele é a expressão final da verdade de que Deus realmente está conosco (Emanuel), não para nossa destruição, mas para nossa redenção". ${ }^{118}$

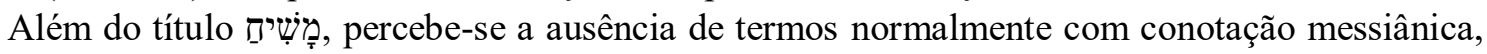
como é o caso de (זטְׁ (ramo, rebento) em Is 11,1 ou até mesmo (dominador) em Mq 5,1. ${ }^{119}$ Albares Martin entende que "Deus Forte" poderia referir-se a esse messias somente em Is 10,21. ${ }^{120}$ Talvez chame

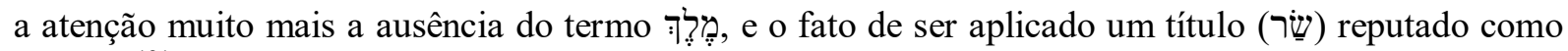
inferior. ${ }^{121}$ Entretanto, poderia refletir o criticismo isaiano à realeza em oráculos messiânicos como Is 7,9 e $11 .{ }^{122}$ Ainda assim, é "evidente à luz da linguagem que o que está sendo expresso não é apenas um rei humano"; "é claramente (...) o Messias", ${ }^{123}$ como já interpretava o Targum. ${ }^{124}$ Seguramente, esse menino (também descrito em Is 11,1-5) nos é apresentado como o cumprimento último do sinal do Emanuel, o "rei final, o rei que porá fim a todos os reis", o qual manifestará a verdade do "Deus conosco". ${ }^{25}$

\footnotetext{
${ }^{111}$ LIMA, M. L. C., Salvação entre juízo, conversão e graça, p. 55.

112 ALBARES MARTIN, J. L., Mesianismo, p. 438.

${ }^{113}$ DE JONGE, M., Messiah, p. 780.

${ }^{114}$ ALBARES MARTIN, J. L., Mesianismo, p. 442-443.

${ }^{115}$ WATTS, J. D. W., Isaiah 1-33, p. 174.

116 BLENKINSOPP, J., Isaiah 1-39, p. 250.

${ }^{117}$ KAISER, O., Isaiah 1-12, p. 213.

118 OSWALT, J., Comentários do Antigo Testamento, p. 300-301.

${ }^{119}$ SOGIN, J. A., מְלְ, p. 676-677.

${ }^{120}$ ALBARES MARTIN, J. L., Mesianismo, p. 442.

${ }^{121}$ SEYBOLD, K., מִכלְר, p. 356.

${ }^{122}$ SEYBOLD, K., מֶֶ? p. p. 364.

123 OSWALT, J., Comentários do Antigo Testamento, p. 305.

${ }^{124}$ GRAY, G. B., A Critical and Exegetical Commentary on the Book of Isaiah, p. 172. O texto em 9,5 do Targum diz: "seu nome é chamado desde a eternidade: Maravilhoso em conselho, Deus forte, o que vive para sempre - o Messias, cuja paz será grande nos seus dias" (COMPREHENSIVE ARAMAIC LEXICON, Targum Jonathan to the Prophets. Base de dados em Software Bíblico Logos, Versão 7).

${ }^{125}$ OSWALT, J., Comentários do Antigo Testamento, p. 307-308.
} 
Após refletir sobre a suposta influência do protocolo egípcio de entronização e a questão da "adoção" do rei por Deus com base em S1 2,7, Roberts conclui, embora não fale exatamente de um personagem messiânico, que "devemos ao menos considerar a possibilidade de que os interlocutores fictícios do oráculo inteiro" são os "membros da divina corte de YHWH", "refletindo o jubiloso assentimento do conselho divino ao novo rei", filho de YHWH. ${ }^{126}$ Esta figura messiânica "coroa" a teologia já expressa desde $2 \mathrm{Sm} 7$ acerca da aliança davídica. ${ }^{127}$ Por esta razão Lucas mostra essa passagem sendo aplicada (citada de forma adaptada) a Jesus em 1,32-33 como cumprindo as expectativas acerca da renovação da dinastia davídica. ${ }^{128}$

\section{Conclusão}

Não obstante as dificuldades da transmissão do texto - e consequentemente de tradução -, a análise de Is 8,23-9,6 mostrou como vários dados depõem a favor de uma datação na época josiânica. Mais importante do que concluir pela redação não-isaiana dessa perícope, é analisar o seu caráter escatológico: apesar de satisfazer a vários itens listados por diversos autores, falta à passagem o aspecto futurista, pois fala de algo que já ocorreu - a entronização do rei Josias. Se por um lado o texto não é escatológico, por outro é messiânico: o menino que nasce é uma figura messiânica; o tom ufanista se alarga pela expectativa de que esse rei seja aquele que porá fim à opressão e às guerras, e reconduzirá o reino de Judá aos seus dias de glória. O entusiasmo inclui até mesmo uma aura divina em torno dessa figura messiânica, o que facilitou a interpretação lucana - e, consequentemente, a cristã tradicional. O estudo comprovou como pressupostos da hermenêutica posterior são projetados para um determinado texto bíblico; e que não necessariamente escatologia e messianismo são conceitos "inseparáveis".

\section{Referências bibliográficas}

ALBARES MARTIN, J. L. Mesianismo. In: BARRIOCANAL GÓMEZ, J. L. Diccionario del Profetismo Biblico. Burgos: Monte Carmelo, 2007. p. 442-443.

ALONSO-SCHÖKEL, L. Dicionário Bíblico Hebraico-Português. São Paulo: Paulus, 1997.

ALONSO-SCHÖKEL, L.; SICRE DIAZ, J. L. Profetas I. São Paulo: Paulus, 1988.

BEALE, G. K.; CARSON, D. A. Comentário do uso do Antigo Testamento no Novo Testamento. São Paulo: Vida Nova, 2014

BLENKINSOPP, J. Isaiah 1-39: A New Translation with Introduction and Commentary. Anchor Yale Bible. New Haven / London: Yale University Press, 2008. v. 19.

BROWN, F., DRIVER, S. R.; BRIGGS, C. A. The Brown-Driver-Briggs Hebrew and English Lexicon. Oxford: Clarendon Press, 1977.

BUSHELL, M. S. Bible Works for Windows. Version 10. Norfolk, Va, Bible Works, LLC, 2015.

CARLSON, R. A. The Anti-Assyrian Character of the Oracle in Is. ix 1-6. Vetus Testamentum, v. 24, p. 130-135, 1974.

COMPREHENSIVE ARAMAIC LEXICON. Targum Jonathan to the Prophets. Cincinanati: Hebrew Union College, 2005. Base de dados em Software Bíblico Logos, Versão 7.

CROOK, M. B. Did Amos and Micah Know Isaiah 9,2-7 and 11,1-9? Journal of Biblical Literature, v.73, p. 144-151, 1954.

FISCHER, B.; WEBWE, R. Biblia Sacra: iuxta vulgatam versionem. Editionem quintam emendatam retractatam praeparavit Roger Gryson. Stuttgart: Bibelgesellschaft; São Paulo: Sociedade Bíblica do Brasil, 2007.

\footnotetext{
${ }^{126}$ ROBERTS, J. M., Whose Child Is This? Reflections on the Speaking Voice in Isa 9:5, p. 129.

${ }^{127}$ SICRE DIAZ, J. L., Introdução ao profetismo bíblico, p. 426-427.

${ }^{128}$ BEALE, G. K.; CARSON, D. A., Comentário do uso do Antigo Testamento no Novo Testamento, p. 327.
} 
GRAY, G. B. A Critical and Exegetical Commentary on the Book of Isaiah: I-XXXIX. International Critical Commentary. New York: C. Scribner's Sons, 1912.

DE JONGE, M. "Messiah". In: FREEDMAN, D. N. (org.). The Anchor Yale Bible Dictionary. New York: Doubleday, 1992. p. 780. v. 4.

KAISER, O. Isaiah 1-12: a Commentary. 2nd. ed. completely rewritten. Philadelphia, Pa.: Westminster, 1983.

KITTEL, R. et al. Biblia Hebraica Stuttgartensia. Editio quinta emendata. Stuttgart: Deutsche Bibelstiftung, 1997.

KOEHLER, L., et al. The Hebrew and Aramaic Lexicon of the Old Testament (electronic ed.). Leiden / New York: E. J. Brill, 1999.

JASTROW, M. A Dictionary of the Targumim, the Talmud Babli and Yerushalmi, and the Midrashic Literature: Volume I and II. London: Luzac \& Co.; New York: G. P. Putnam's Sons, 1903. LANGE, J. P. et al. A Commentary on the Holy Scriptures: Isaiah. Bellingham, WA: Lexham Press, 2008.

LEXHAM PRESS. 1Q Isaiah a. Bellingham, WA: Lexham Press, 2010. Base de dados em Software Bíblico Logos, Versão 7.

LIMA, M. L. C. Exegese Bíblica: Teoria e Prática. São Paulo: Paulinas, 2014.

LIMA, M. L. C. Mensageiros de Deus: Profetas e profecias no antigo Israel. Rio de Janeiro: PUC-Rio; São Paulo: Reflexão, 2012.

LIMA, M. L. C. Salvação entre juízo, conversão e graça: a perspectiva escatológica de Os 14,2-9. Roma: Pontifícia Università Gregoriana, 1998.

MOWINCKEL, S. He That Cometh. Oxford: Blackwell, 1956.

NICCACCI, A. Sintaxis del Hebreo Bíblico. 2. ed. Navarra: Editorial Verbo Divino, 2002.

OCKINGA, B. Hatshepsut's Appointment as Crown Prince and the Egyptian Background to Isaiah 9:5. In: BAR, S.; KAHN, D.; SHIRLEY, J. J. (Eds.). Egypt, Canaan and Israel: Imperialism, Ideology and Literature. Proceedings of a Conference at the University of Haifa, 3-7 May 2009. Leiden / Boston: Brill, 2011. p. 252-267

OSWALT, J. Comentários do Antigo Testamento: Isaías. São Paulo: Editora Cultura Cristã, 2011. v. 1 (capítulos 1 a 39).

RAHLFS, A. Septuaginta: id est Vetus Testamentum graece iuxta Lxx interpretes. Ed. 5. Stuttgart: Württembergische Bibelanstalt, 1952. 2 vol.

RIGNELL, L. G. A Study of Isaiah 9:2-7. Lutheran Quaterly, v.7, p. 31-35, 1955.

ROBERTS, J. M. Whose Child Is This? Reflections on the Speaking Voice in Isa 9:5. Harvard Theological Review, v.90, p. 115-129, 1997.

SAUCY, R. L. Is Christ the Fulfillment of National Israel's Prophecies? Yes and No! Master's Seminary Journal, v.28, p. 17-39, 2017.

SEYBOLD, K. מֶּרֶ. In: BOTTERWECK, G. J.; RIGGREN, H.; FABRY, H. (Org.). Theological Dictionary of the Old Testament. Grand Rapids: William B. Eerdmans Publishing Co., 1997. p. 346375. v. 8.

SICRE DIAZ, J. L. Introdução ao profetismo bíblico. Petrópolis: Vozes, 2016.

SIMIAN-YOFRE, H. Diacronia: os métodos históricos-críticos. In: SIMIAN-YOFRE, H. (Org.). Metodologia do Antigo Testamento. São Paulo: Loyola, 2000. p. 73-108.

SIMIAN-YOFRE, H. Testi isaiani dell'avvento. Bologna: Edizone Dehoniane Bologna, 1996.

SOGIN, J. A. מֶֶֶ. In: JENNI, E.; WESTERMANN, C. (Org.). Theological Lexicon of the Old Testament. Peabody, MA: Hendrickson Publishers, 1997. p. 672-680. 
SWEENEY, M. Isaiah 1-39: With an Introduction to Prophetic Literature. The Forms of the Old Testament Literature. Grand Rapids, MI: William B. Eerdmans Publishing Company, 1996. v. 16.

VON RAD, G. Teologia do Antigo Testamento. Tradução Francisco Catão. $2^{\mathrm{a}}$. Ed. São Paulo: ASTE / Targumim, 2006.

WATTS, J. D. W. Isaiah 1-33. Revised Edition. Nashville: Thomas Nelson, Inc, 2005. (Word Biblical Commentary, 24).

WATSON, W. G. E. Classical Hebrew Poetry: a Guide to its Techniques. 2nd. ed. with corr. Sheffield: Sheffield Academic Press, 1995.

WILDBERGER, H. A Continental Commentary: Isaiah 1-12. Minneapolis, MN: Fortress Press, 1991. YOUNG, E. The Book of Isaiah, Chapters 1-18. Grand Rapids, MI: Wm. B. Eerdmans Publishing Co., 1965. v. 1.

Doaldo Ferreira Belem

Mestre em Teologia pela Pontifícia Universidade Católica do Rio de Janeiro Pesquisador da Universidade do Estado do Rio de Janeiro

Rio de Janeiro / RJ - Brasil E-mail: doaldofb@uol.com.br

Recebido em: 19/12/18

Aprovado em: 06/02/19 